\title{
Research on Ecological Benefit of Land Use in Fujian Province Chen Qiang ${ }^{1,2, a}$ \\ ${ }^{1}$ college of geographical sciences,Fujian Normal University,Fuzhou 350007,China \\ 2 School of Business Administration, Fujian Jiangxia University,Fuzhou 350108,China \\ a81975429@qq.com
}

Keywords: land use, ecological benefit, hierarchy fuzzy, evaluation

\begin{abstract}
. in order to enhance the ecological benefit efficiency of land use as well as the aim of resources and environment protection, this paper by constructing index system establishment and design of land use ecological benefit, the evaluation index adopts comprehensive integrated weight method as well as through linear weight way to integrate the obtained weight of subjective and objective perspective to confirm the final weight index. Of which, the Analytic hierarchy process obtained by subjective weight method, objective weight method still uses variation coefficient method, after combining with land resources data information of Fujian to make analysis, and then it masters land use condition, which paves base for the enhancement of land use and ecological benefit of Fujian.
\end{abstract}

\section{Introduction}

Land arrangement means using all kind of measures to make comprehensive arrangement on land, water, road, forest and country, enhancing farmland quality, increasing farmland square as well as enhancing production capacity agriculture and improving the behaviors ${ }^{[1,2]}$ adopted by ecological environment in agriculture and country. Land arrangement is the important measure to enhance land quality and promote intensification utilization of land. At the same time of quick development in land use benefit, the unreasonable use causes problems such as excessive consumption of resources and aggravation in environment pollution, increasingly fierce contradiction between human and land etc, regional ecological environment becomes increasingly sensitive and fragile, reduction in ecological environment quality becomes increasingly obvious in effectiveness hinder of land use. Therefore, how to deal with relations between regional land use and ecological environment has become to be the hot problem of society at present.

This paper uses regional land use and coordinated development of ecological environment as start point, it chooses Fujian province as research region and constructs coordinated development evaluation model of land use and ecological environment based on theory such as sustained development and coordination etc, it combines with qualitative and quantitative method to make research on level of coordinated level. In addition, it uses AHP to calculate weight of every index, and adopts comprehensive evaluation method based on fuzzy mathematics to make evaluation and quantitative evaluation on ecological benefit of land use, it is expected to provide science base for research and practice of comprehensive benefit evaluation of land use.

\section{Construction on ecological benefit index system evaluation model of land use}

Land use and coordinated development system of ecological environment is the complicated system composed of multiple factors, the coordinated development relations of land use sub-system and ecological environment sub-system needs to establish one relatively complete index system. It divides index system into 2 sub-systems of land use and ecological environment, the system includes target layer, field layer, standard layer and index layer. Of which, the affinity relation evaluation score of land use and ecological environment is respectively target layer. Field layer is land use benefit and ecological environment benefit. Land use sub-system includes 3 standard layers such as land use structure, land input and output benefit, population resources and life quality. Ecological environment 
sub-system includes 3 standard layers such as ecological environment pressure, ecological environmental protection, and ecological environment level. Index layer divides standard layer into several detailed indexes. Coordinated development relations of land use and ecological environment are indicated by figure 1 .

In the construction of index evaluation system, it needs to be indicated that some detailed indexes researched by this paper such as land proportion without being used, transportation land use proportion, population density etc are moderate indexes, but in the social and economic development stage at present, these moderate indexes indicate certain directivity or reverse, so it converts these indexes in research into positive or negative treatment.

The coupling relation evaluation model of land use and ecological environment coordinated development is constructed based on coordination model of variation coefficient, its internal structure includes benefit and index evaluation function of land use sub-system, benefit index evaluation model of ecological environment sub-system, as well as comprehensive benefit and index evaluation function of land use and ecological environment, coordination function of land use and ecological environment as well as coordination development function.

(1) The benefit evaluation model of land use sub-system benefit and ecological environment sub-system is as follows:

$$
\begin{aligned}
& F(x)=\sum_{i=1}^{m} W_{i} X_{i} \\
& G(y)=\sum_{j=1}^{n} P_{j} Y_{j}
\end{aligned}
$$

Figure 1 Evaluation index system

In the formula, $\mathrm{F}(\mathrm{x}), \mathrm{G}(\mathrm{y})$ are respectively benefit index of land use sub-system and ecological environment sub-system, $\mathrm{Wi}, \mathrm{P}_{\mathrm{j}}$ is respectively weight of land use sub-system and ecological environment sub-system, $X_{i}, Y_{j}$ is respectively is the standardization value of land use sub-system, ecological environment sub-system index.

(2) Ecological comprehensive benefit index evaluation of land use:

$$
T=\alpha F(x)+\beta G(y)
$$

In the formula, $\alpha, \beta$ is respectively the weight value of land use sub-system benefit and ecological environment sub-system in comprehensive benefit, in view of the same effect of land use sub-system and ecological environment sub-system in the evaluation system, so $\alpha=\beta=0.5$. T is the comprehensive benefit evaluation index of land use and ecological environment.

(3) Coordination function of land use and ecological environment as well as coordination and development function:

$$
\begin{gathered}
\mathrm{c}=\left\{\frac{F(x) * G(y)}{\frac{F(x)+\mathrm{G}(y)}{2}}\right\}^{k} \\
D=\sqrt{C * T}
\end{gathered}
$$

In the formula, $\mathrm{C}$ is coordination, $\mathrm{T}$ is the comprehensive benefit evaluation index of land use and ecological environment. $D$ is coordination, $F(x), G(y)$ is respectively benefit index of land use and ecological environment sub-system, when product of $F(x)$ and $G(y)$ is maximum, the the comprehensive benefit of land use and ecological environment is maximum, the number grade of combined coordination between land use and ecological environment $\mathrm{K} \geq 2, \mathrm{k}$ takes 2 in this paper.

Coordination can indicate the coordinated relations between land use sub-system and ecological environment sub-system, bu it can only reflect coordinated relations of 2 sub-system, the larger coordination may be coordinated development of low level and it can not reflect the overall function or development level of land use and coordinated development of ecological environment, so introducing into coordination concept can not only reflect synchronization of land use and ecological environment, but also can indicate overall comprehensive strength of research regions. 


\section{Data processing and evaluation method}

This paper chooses data of Fujian province as sample to explain change trend of land use in Fujian and analyze state of land use as well as obtain countermeasure illumination. It makes comprehensive evaluation on land use benefit in Fujian establishing city so as to make horizontal comparison. This paper adopts Min-max method to make standardization processing on original data. Because

The standardization value of positive index of $\mathrm{j}$ index in i year $=\frac{x_{i j}-\min \left(x_{j}\right)}{\max \left(x_{j}\right)-\min \left(x_{j}\right)}$

The standardization value of positive index of $\mathrm{j}$ index in i year $=\frac{\max \left(x_{j}\right)-x_{i j}}{\max \left(x_{j}\right)-\min \left(x_{j}\right)}$

Of which, $\mathrm{X}$ is the variable of sample, $\mathrm{Xij}$ is the original vale of index for $\mathrm{j}$ index in the $\mathrm{i}$ year and $\min \left(\mathrm{x}_{\mathrm{j}}\right)$ is the maximum value and minimum value ofj index. The calculation result is indicated by the following table 1.

Table 1 Result of original value without dimension

\begin{tabular}{|c|c|c|c|c|c|c|c|}
\hline Index & $\begin{array}{l}\text { nondimen } \\
\text { sionalizati } \\
\text { on }\end{array}$ & Index & $\begin{array}{l}\text { nondimen } \\
\text { sionalizati } \\
\text { on }\end{array}$ & Index & $\begin{array}{l}\text { nondimen } \\
\text { sionalizati } \\
\text { on }\end{array}$ & Index & $\begin{array}{l}\text { nondimen } \\
\text { sionalizati } \\
\text { on }\end{array}$ \\
\hline X1 & 0.9730 & X10 & 0.9609 & X19 & 1.0000 & X28 & 1.0000 \\
\hline X2 & 0,7763 & X11 & 0.6415 & X20 & 0.4945 & X29 & 0.2152 \\
\hline X3 & 0.6267 & $\mathrm{X} 12$ & 1.0000 & X21 & 0.4375 & X30 & 1.0000 \\
\hline X4 & 1.0000 & X13 & 1.0000 & X22 & 1.0000 & X31 & 1.0000 \\
\hline X5 & 1.0000 & X14 & 0.9778 & X23 & 1.0000 & X32 & 0.9838 \\
\hline X6 & 0.9551 & X15 & 1.0000 & X24 & 1.0000 & X33 & 0.9916 \\
\hline X7 & 1.0000 & X16 & 1.0000 & X25 & 0.9848 & & \\
\hline X8 & 1.0000 & X17 & 0.9798 & X26 & 1.0000 & & \\
\hline X9 & 0,9972 & X18 & 0.9826 & X27 & 1.0000 & & \\
\hline
\end{tabular}

In order to maintain systematicness and integrity of system, confirmation on evaluation index still adopts comprehensive integrated weighting method to confirm the final index weight through linear weight way to integrate subjective and objective perspective. Of which, the objective weight of medium AHP obtained by subjective weight method still adopts variation coefficient method.

In the information theory, entropy is one kind of measurement on uncertaintity. The more of information amount, the smaller of entropy. The smaller of information amount, the bugger of uncertaintity. According to characteristic of entropy, we can judge randomness and disorder degree of one event by calculating entropy value, we can also use entropy value to judge dispersion degree of certain index, the large of dispersion degree, the larger effect of this index on comprehensive evaluation. Entropy method is one kind of objective wieghting method, it determines index wieght according to relative change degree of index and effect on the whole system, index with larger change degree has larger weight.

First, it will standardize index, calculate the prportion $\mathrm{y}_{\mathrm{ij}}$ of index value of the $\mathrm{j}$ item in the i year:

$$
y_{i j}=\frac{x_{i j}}{\sum_{i=1}^{m} x_{i j}}, i=1,2, \cdots, m ; j=1,2, \cdots, 11,\left(0 \leq y_{i j} \leq 1\right)
$$

Second, calculate entropy of the $\mathrm{j}$ index:

$$
e_{j}=\frac{\sum_{i=1}^{m} y_{i j} \operatorname{Iny}_{i j}}{\operatorname{Iny}_{i j}}, i=1,2, \cdots, m ; j=1,2, \cdots, 11
$$

Third, calculate the differential coefficient $d_{j}$ of the $j$ index:

$$
d_{j}=1-e_{j}, j=1,2, \cdots, 11
$$

Fourth: calculate the weight $\mathrm{W}_{\mathrm{j}}$ of every index: 


$$
w_{j}=\frac{d_{j}}{\sum_{i=1}^{m} d_{j}}, j=1,2, \cdots, 11
$$

Variation coefficient is to confirm index weight according to mutial relations among evaluation indexes as well as internal variation information of index. The coupling relations evaluation of land use and ecological environment coordinatd development is the complicated system composed of multiple indexes, in this system with multiple indexes, if certain index can clearly diustinguish every participating sample, the it indicates that this index has rich identification information in evaluation system, this index should be given larger weight value. The calculation step of variation coefficient is as follows:

(1) calculate the average and variance of every index

$$
\begin{gathered}
\overline{X_{j}}=\frac{1}{n} \sum_{i=1}^{m .} X_{i j} \\
S_{j}^{2}=\frac{1}{n-1} \sum_{i=1}^{n}\left(x_{i j}-\overline{X_{j}}\right)^{2}
\end{gathered}
$$

(2) calculate variation coefficient of every index

$$
V_{j}=\frac{S_{j}}{\overline{X_{j}}}
$$

(3) Calculate weight of every index

$$
W_{j}=\frac{v_{j}}{\overline{\sum_{i=1}^{m} V_{j}}}
$$

The integrated weight method mainly includes multiplicative integrate method and addition integrated method, relatively speaking, because addition integrated method has smaller calculation amount and it is simple to use, so this research uses weighting integrated method, the formula is as follows:

$$
W_{j}=k_{1} p_{j}+k_{2} q_{j}
$$

In the formula, $\mathrm{k}_{1}, \mathrm{k}_{2}$ is respectively weight coefficient, $\mathrm{P}_{\mathrm{j}} 、 \mathrm{q}_{1}$ is respectively the obtained weight by different weight methods in the $\mathrm{j}$ index, $\mathrm{W}_{\mathrm{j}}$ is the obtained weight by comprehensive integrated

\begin{tabular}{|c|c|c|c|c|c|c|c|}
\hline Index & $\begin{array}{l}\text { Variation } \\
\text { coefficien } \\
\text { t weight }\end{array}$ & $\begin{array}{l}\text { Entropy } \\
\text { weight }\end{array}$ & $\begin{array}{l}\text { Comprehe } \\
\text { nsive } \\
\text { integrated } \\
\text { weight }\end{array}$ & Index & $\begin{array}{l}\text { Variation } \\
\text { coefficien } \\
\text { t weight }\end{array}$ & $\begin{array}{l}\text { Entropy } \\
\text { weight }\end{array}$ & $\begin{array}{l}\text { Comprehe } \\
\text { nsive } \\
\text { integrated } \\
\text { weight }\end{array}$ \\
\hline $\mathrm{X} 1$ & 0.0037 & 0.0001 & 0.0019 & X18 & 0.0044 & 0.0002 & 0.0023 \\
\hline X2 & 0.0225 & 0.0049 & 0.0137 & X19 & 0.0165 & 0.0026 & 0.0095 \\
\hline X3 & 0.0421 & 0.0171 & 0.0296 & X20 & 0.0779 & 0.0480 & 0.063 \\
\hline $\mathrm{X} 4$ & 0.0073 & 0.0005 & 0.0039 & X21 & 0.1170 & 0.1102 & 0.1136 \\
\hline X5 & 0.1790 & 0.2960 & 0.2375 & X22 & 0.0478 & 0.0199 & 0.0338 \\
\hline X6 & 0.1218 & 0.1324 & 0.1271 & X23 & 0.0201 & 0.0034 & 0.0118 \\
\hline X7 & 0.1392 & 0.1763 & 0.1578 & X24 & 0.0055 & 0.0003 & 0.0029 \\
\hline X8 & 0.1524 & 0.2247 & 0.1885 & X25 & 0.0043 & 0.0002 & 0.0022 \\
\hline
\end{tabular}
weight method.

\section{Data analysis and demonstration result analysis}

According to every index data answer of 9 cities in Fujian province, the calculation result is indicated by table 2 .

Table 2 Evaluation system index weight of land use and ecological benefit of cities in Fujian 


\begin{tabular}{llllllll}
\hline X9 & 0.0160 & 0.0024 & 0.0092 & X26 & 0.0934 & 0.0724 & 0.0829 \\
X10 & 0.0038 & 0.001 & 0.0020 & X27 & 0.0206 & 0.0036 & 0.0121 \\
X11 & 0.0457 & 0.0204 & 0.0331 & X28 & 0.1120 & 0.1095 & 0.1107 \\
X12 & 0.0409 & 0.0159 & 0.0284 & X29 & 0.2111 & 0.3047 & 0.2579 \\
X13 & 0.0395 & 0.0147 & 0.0271 & X30 & 0.2007 & 0.2874 & 0.2440 \\
X14 & 0.0159 & 0.0023 & 0.0091 & X31 & 0.0055 & 0.0003 & 0.0029 \\
X15 & 0.0662 & 0.0411 & 0.0537 & X32 & 0.0151 & 0.0020 & 0.0085 \\
X16 & 0.0712 & 0.0470 & 0.0591 & X33 & 0.0689 & 0.0383 & 0.0536 \\
X17 & 0.0120 & 0.0014 & 0.0067 & & & & \\
\hline
\end{tabular}

Coordination is used to measure the degree of system internal or external factors on mutual coordination in the development process, which indicates trend from disorder to order, it is the quantitative index to coordinate state degree. Land use benefit evaluation should not only calculate index value of economy, society and ecological benefit as well as comprehensive evaluation index, the single one is not enough to reflect coordination of land in the use process. So it needs to calculate mutual degree of every sub-system of land use benefit to judge whether these 3 kinds of benefits are balanced or not. Generally speaking, the closer of evaluation value of ecological sub-system in regional land use benefit, the more coordination of land use process.

This paper uses coordination coefficient evaluation to evaluate coordination relation, the calculation formula is as follows:

$$
F_{i}=1-\frac{E_{i}}{H_{i}}(i=1,2,3, \cdots, n)
$$

Of which, Fi is coordination coefficient of agricultural land benefit, Ei is the standard difference of ecological evaluation index of land use in the $\mathrm{i}$ year, $\mathrm{Hi}$ is the average value of 3 sub-system evaluation index of land use benefit in the i year. The coordination theory thinks that Fi is from 0 to 1 , the larger of its value, the larger of its value, which indicates that it has high coordination. When coordination coefficient is much closer to 1 , which indicates that the coordination of 3 sub-system in this year is better, on the contrary, the coordination is close to 0 , which indicates the discordance of these 3 sub-system in this year. Generally, when $\mathrm{F}>0.7$, every sub-system of land use benefit in Liancheng country is highly coordinated, when $0.4 \mathrm{~S} \leq \mathrm{FiS} \leq 0.7$, land use benefit system in Liancheng country is basically coordinated, when $\mathrm{Fi}<0.4$, agricultural land use benefit is not coordinated.

It applies index weight by evaluation model and weight function formula to calculate, we can scores of land use sub-system and ecological environment sub-system as well as comprehensive benefit score, we can also get coordination of land use and ecological environment as well as coordination development degree of land use and the overall ecological environment. It is indicated by table 3:

Table 3 Evaluation result on land use and ecological environment coordinated development in Fujian province

\begin{tabular}{llllll}
\hline year & $\begin{array}{l}\text { Land } \\
\text { efficiency }\end{array}$ & $\begin{array}{l}\text { use } \\
\text { ecological } \\
\text { environment } \\
\text { benefit }\end{array}$ & $\begin{array}{l}\text { comprehensiv } \\
\text { e benefit }\end{array}$ & coordination & $\begin{array}{l}\text { Coordination } \\
\text { development }\end{array}$ \\
\hline 2010 & 0.4823 & 0.4524 & 0.4673 & 0.9979 & 0.6829 \\
\hline 2011 & 0.5496 & 0.5034 & 0.5265 & 0.9961 & 0.7242 \\
\hline 2012 & 0.6425 & 0.6618 & 0.6521 & 0.9996 & 0.8074 \\
\hline 2013 & 0.7634 & 0.5101 & 0.6367 & 0.9224 & 0.7664 \\
\hline 2014 & 0.8897 & 0.5691 & 0.7294 & 0.9057 & 0.8128 \\
\hline
\end{tabular}

From table 3 we can see land use efficiency, ecological benefit and comprehensive benefit index of Fujian from 2010 to 2015 has increased from the overall, but it has fluctuation in the detailed change process. Of which, land use efficiency index increases year by year, the annual growth speed is 6.53\%. The ecological environment benefit index wholly increases, but it has periodic fluctuation. The 
ecological environment benefit presents enhancement state form 2010 to 2012; ecological benefit index reduces to 0.5101 in 2013. Benefit index starts to rise after 2013 and reaches 0.7012 in 2015. At the same time, land use is relatively similar to change trend of ecological comprehensive benefit and ecological benefit index, the overall level is in the increase level, but it has reduction in 2013 and continue to present increase trend afterwards.

As for the causes of benefit index, it is mainly because that time from 2010 to 2015 is the period for Fujian to strengthen strength of attracting investment, accelerating industrialization and urbanization to move forward. From the average land input index, it also demonstrates the quick growth of land input, which has great acceleration effect on increase of land use efficiency in Fujian province. As for ecological environment benefit, land use and comprehensive benefit of ecological environment, ecological environment state and man-made pollution treatment has great effect on changes in ecological environment benefit index and comprehensive benefit index. In research of this paper, ecological environment index and comprehensive benefit index has similar change trend. Fujian promotes industrialization progress, the average land input increase and output obviously increases, and it strengthens enforcement strength to make regulation, updating and elimination on enterprises with heavy pollution, large consumption and low benefit, which increases treatment capacity of city and industry pollution, enlarges city greening land square and improves ecological environment. As it is indicated by figure 2, it is the curve diagram of land use, ecological environment benefit and comprehensive benefit index.

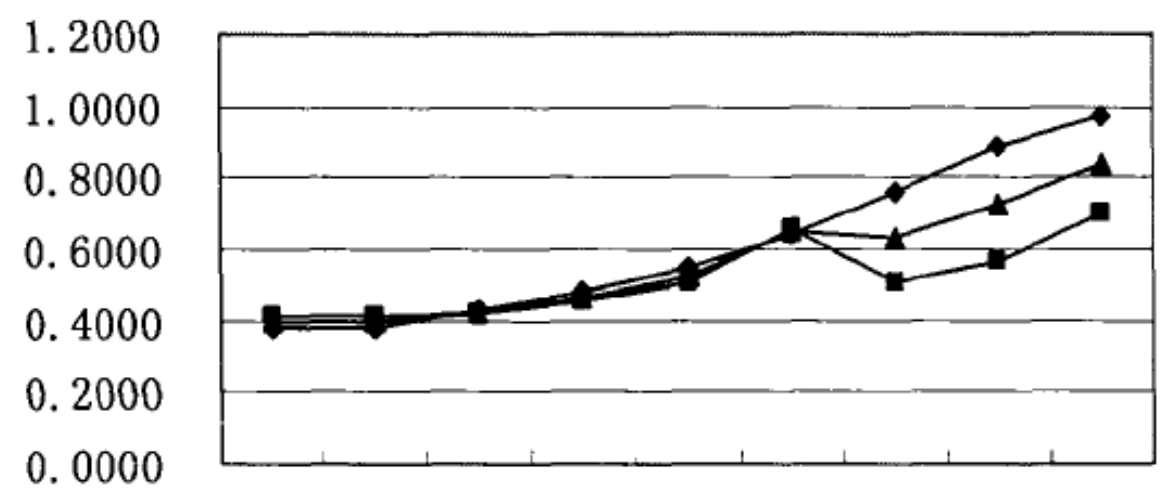

Figure 2 Curve diagram of land use, ecological environment benefit and comprehensive benefit index

In order to enhance land benefit of Fujian province, gradually strengthen environment protection strength, strengthen the capacity of resisting natural disaster, increase harvest yield and promote stable development of graziery. It optimizes planting structure, increases added-value of subsidiary agricultural products, adjusts and promotes industry structure of subsidiary agricultural products, accelerates subsidiary agricultural products develops from rough processing to expert, delicate, special and new directions. Developing 3-dimension agriculture, improving single grain plant situation is favorable to improve environment, realize virtuous cycle, at the same time it is favorable to display the land resources advantage in hill region, realize comprehensive development, which has important meanings on how to develop leisure agriculture in Liancheng country.

\section{Conclusion}

Land use problem and ecological environment problem is the focus problems concerned by society at present; it together has important effect on economic development ant and social harmony and advancement. Relations between land use and ecological environment is complementary and mutually affected, reasonable use of land and better ecological environment is the key and precondition of sustained development of region. This paper uses Fujian as research region, it makes analysis on land use ecological benefit, and uses coordination model to measure and make research on dynamic change of land use ecological benefit of Fujian from 2010 to 2015 on this basis. It uses 
hierarchical clustering method and combines with space difference research on land use and coordinated development of ecological environment; it puts forward the coordinated development difference strategy of land use and ecological environment, which has important meanings to make research on regional sustained development. From the evaluation, we can see the existing problems of land arrangement in hill regions, enhancing some index has become to be the key point of land arrangement in the future of this region. It requires the land arrangement work in the future should gradually change idea and increase investment in farmland and forest construction as well as put into investment to enhance farmland especially for the farmland quality, gradually increase economic benefit and social benefit, and finally reaches the aim of increasing comprehensive benefit.

\section{References}

[1] Fan Jinmei. Research on Benefit Evaluation of Land Arrangement, Vol 14, 2003,14-15.

[2] Li Xia, Liu Xiuhua. Discussion on Comprehensive Benefit Evaluation of Land Arrangement. Journal of Southeast Agriculture University (social and science version),Vol 2(4),2004,pp 5-7.

[3] Li Guoan. Application Factor Analysis Method in Benefit Analysis and Evaluation After Land Arrangement. Journal of Ningbo University (engineering version), Vol 18(1),2005,pp 20-23.

[4] Zhang Fugang,Hao Jinxia,Li Xulin etc.Coordination Evaluation of Country Land Use-Take Quzhou Country of Hebei Province for Example. Notice of Water and Land Conversation. Vol 25(2),2005,pp 63-68.

[5] Peng Buzhuo, Anxudong, Chen Fu etc. Sustained Use Research on Land Resources in Changjiang River delta. Journal of Naural Resources, Vol 7,2001,pp 306-311.

[6] Zhang Yan, Zhang Hong, Peng Buzhuo. Coordinated Evaluation of Land Resources, Environment and Economic Development-Take Tongzhou for Example. Changjiang Water Shed Resources and Environment, Vol 28(4),2008,pp 529-534.

[7] Li Zhibin. One Kind of City Land Use and Benefit Comprehensive Evaluation Method. City Planning,2000,pp 62-63

[8] Gong Jiping, Shi Peiji, Pan Jihu. Analysis on Lanzhou Land Use and Benefit Based on DNA.Notice of Water and Land Conservation, Vol 05,2011,pp163-166. 